\title{
Scale-dependent variability in seabird abundance
}

\author{
David C. Schneider ${ }^{1,2}$ \& David Cameron Duffy ${ }^{2}$ \\ 'Newfoundland Institute for Cold Ocean Science, Memorial University, St. John's, Newfoundland A1B 3X7, Canada \\ ${ }^{2}$ FitzPatrick Institute of African Ornithology, University of Cape Town, Rondebosch 7700, South Africa
}

\begin{abstract}
Patchiness of co-occurring species of seabirds in an anisotropically structured physical regime was investigated by making continuous counts of birds along 4 transects in the Benguela upwelling region, in the southeastern Atlantic Ocean. Birds were highly aggregated at spatial scales ranging from 0.3 to $23 \mathrm{~km}$. This variability could not be modeled by standard statistical distributions, including negative binomial and gamma distributions. Patchiness was scale-dependent, as indicated by significant changes in moment ratios with change in frame size (measurement interval). Patchiness was not isotropic (independent of transect orientation). Extensive aggregation was observed in 3 out of 5 abundant species along an east-west transect, but was not found in any of these 5 species along a north-south transect. Extensive aggregation was observed in 4 of the same 5 species when the east-west transect was repeated on the following day. Patch scale along the east-west transect ranged from 6.8 to $20.5 \mathrm{~km}$ on the first passage, and from 11.5 to $23 \mathrm{~km}$ on the second passage. Variation in patch size among species along the same transect indicates that patch scale in seabirds depends on speciesspecific responses to the pelagic environment.
\end{abstract}

\section{INTRODUCTION}

Seabirds forage in an environment where physical processes depend on scale (Stommel 1963) and where biological and physical processes interact to impart scale-dependent spatial structure to planktonic biomass (Platt 1972, Mackas \& Boyd 1979). Scaledependent response by birds to hydrographic structuring of marine ecosystems is suggested by the fact that bird aggregations on the order of 10 to $50 \mathrm{~km}$ in lateral extent have been reported along transects normal to hydrographic features in the California Current (Briggs et al. 1984) and in the Bering Sea (Schneider 1982, Kinder et al. 1983, Woodby 1984). These studies, however, did not test whether aggregation was dependent on scale or dependent on orientation of the transect in these anisotropically structured physical regimes.

The Benguela upwelling ecosystem in the Southeastern Atlantic is characterized by strong cross-shelf gradients in physical properties of the water (Bang 1971), and by patchy distributions of plankton (Andrews \& Hutchings 1980), euphausiids (Thomas 1980), fish (Agenbag 1980), and birds (Abrams \& Griffiths 1981). Shoaling fish (anchovy Engraulis capensis and pilchard Sardinops ocellata) are major prey of seabirds in the region (Crawford \& Shelton 1978).
We used continuous counts along extended transects to investigate variability in bird abundance in the Benguela upwelling ecosystem. Our objectives were to determine (1) whether intensity of bird aggregation was dependent on measurement interval (frame size); (2) whether scale of aggregation depended on orientation of a transect in an anisotropically structured physical regime such as the Benguela upwelling.

Quantitative investigations of marine birds have focused on estimates of mean abundance (Tasker et al. 1984 ) rather than on intensity of aggregation. Standard coefficients of clumping (Pielou 1977, Ripley 1981) are based on the first 2 moments of a frequency distribution (usually the mean and the variance) and may not be adequate to describe some forms of variability. We used moment ratios (Ord 1972) to determine whether spatial variation in bird abundance could be described by standard statistical distributions, including the Poisson, binomial, negative binomial, gamma, and normal distributions. We also used moment ratios to determine whether spatial variation in bird abundance was dependent on measurement interval (frame size) along an extended transect.

A variety of methods have been developed to investigate the scale of aggregation in natural populations. Methods based on the partitioning of independent components of variation (Grieg-Smith 1964) cannot be 
applied to contiguous counts of birds, which can be highly correlated (Schneider 1982). Methods based on spectral decomposition of variability provide a sufficient description of continuous processes, but the nonGaussian character of point processes, such as the occurrence of birds, limits the use of spectral models (Bartlett 1975). Methods based on time-series analysis (Box \& Jenkins 1976) are similarly limited. We used the results of point-process theory (Cox \& Isham 1980) to measure the scale of bird aggregation on cross-shelf and long-shelf transects in the Benguela region.

\section{METHODS}

Birds were counted along 4 transects (Fig. 1) in the southern Benguela region in December 1982. Transect A ran from Saldanha By $\left(33^{\circ} 05^{\prime} \mathrm{S}, 17^{\circ} 56^{\prime} \mathrm{E}\right)$ to Dassen Island $\left(33^{\circ} 25^{\prime} \mathrm{S}, 18^{\circ} 05^{\prime} \mathrm{E}\right)$ on 10 December. Data from this transect were used to test whether variation in bird abundance was independent of scale of measurement. Three more transects were run to test whether variability was independent of transect orientation. Transect $B$ was made on the morning of 18 December and ran from a point outside Hout Bay $\left(34^{\circ} 04.5^{\prime} \mathrm{S}, 18^{\circ} 18^{\prime} \mathrm{E}\right)$ westward across the continental shelf to a point where the water became noticeably bluer $\left(34^{\circ} 05^{\prime} \mathrm{S}, 17^{\circ} 50^{\prime} \mathrm{E}\right)$. Transect $\mathrm{C}$ was run on the same day from a nearby point $\left(34^{\circ} 06^{\prime} \mathrm{S}, 17^{\circ} 50^{\prime} \mathrm{E}\right)$ to a point due south $\left(34^{\circ} 22^{\prime} \mathrm{S}\right.$, $17^{\circ} 50^{\prime} \mathrm{E}$ ). Transect $\mathrm{D}$ was made by repeating Transect $B$ the following day. Transect $D$ ran from a point

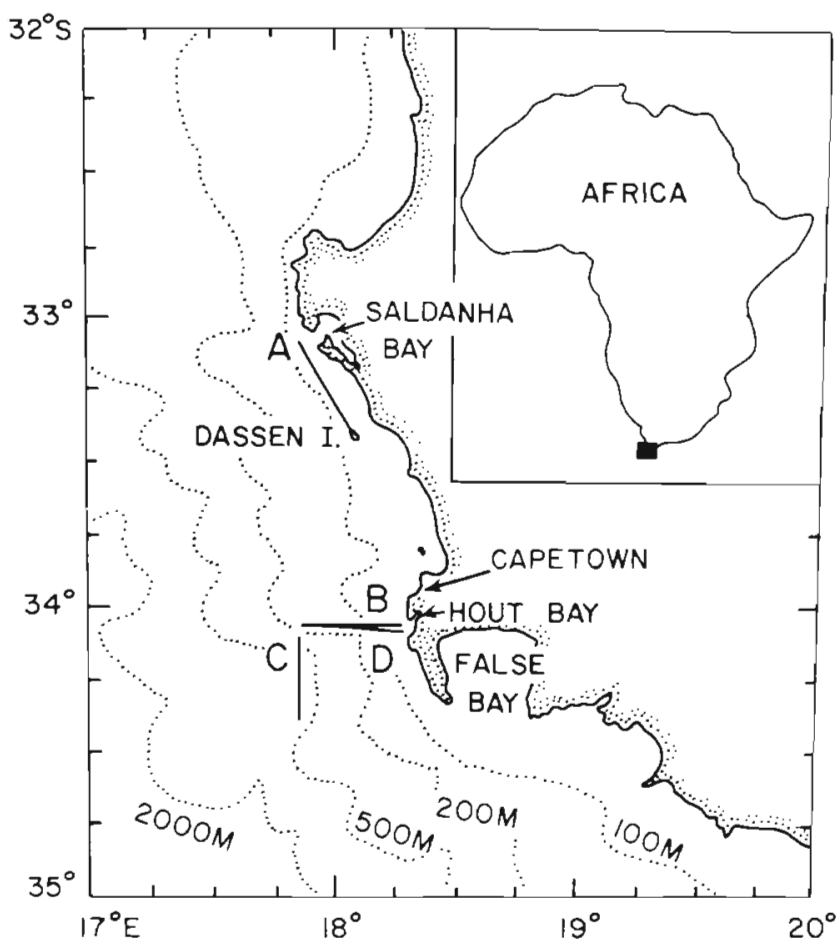

Fig. 1. Location of transects in the Benguela upwelling region outside Hout Bay $\left(34^{\circ} 07^{\prime} \mathrm{S}, 18^{\circ} 20^{\prime} \mathrm{E}\right)$ westward to the same termination point as transect $B$. Blue water was noticeable $7 \mathrm{~km}$ east of the termination point of Transect $D$.

During each transect we recorded, to the nearest minute, the time at which birds were first sighted in a $90^{\circ}$ sector with a radius of $300 \mathrm{~m}$, extending from straight ahead to abeam of midship on the side with better visibility. Birds were identified to the lowest possible taxonomic level, usually species. Environmental data were recorded at the start and at the termination of all transects, which ranged from 30 to 46 $\mathrm{km}$ in length.

Counts were tabulated, by species, in 1 min intervals $\left(\mathrm{x}=\right.$ birds $\left.\min ^{-1}\right)$. Arithmetic mean abundance $(\overline{\mathrm{x}})$, variance $\left(\mathrm{s}^{2}\right)$, skewness (g1) and kurtosis (g2) were computed from the formulae in Sokal \& Rohlf (1981). The Kolmogorov-Smirnov 2-sample test (Sokal \& Rohlf 1981) was used to determine whether deviation from Gaussian variability was significant. Moment ratios (Ord 1972) were used to determine whether spatial variation could be described by standard statistical distributions. For the binomial, Poisson, and negative binomial distributions, the D-statistic is:

$$
\mathrm{D}=\mathrm{S}-2 \mathrm{I}+1=0
$$

where $\mathrm{S}=$ ratio of the third moment to the second moment about the mean; I = ratio of the second moment to the first moment (Ord 1967). For gamma distributions, the D-statistic equals 1 (Ord 1972).

Dependence of variability on measurement interval (frame size) was determined by computing the variance-to-mean ratio ( $\left.\mathrm{I}^{\prime}\right)$ and the D-statistic at integral divisions of the transect, as follows:

$$
I^{\prime}=s^{2} \bar{x}^{-1}=(n-1)^{-1} n I
$$

where $n=$ number of frames transect ${ }^{-1}$. For example, if the transect time $T=120 \mathrm{~min}$, then integral values of n occur at frame intervals $F=1,2,3,4,5,6,8,10,12$, $15,20,24,30,40$, and 60 min frame ${ }^{-1}$. I' will equal 1 if individuals occur at random, I' will be greater than 1 if individuals are clumped. Computations were based on frame intervals measured in minutes. Frame interval was multiplied by ship velocity $\left(\mathrm{km} \mathrm{min}^{-1}\right)$ to obtain frame size $\left(\mathrm{km}\right.$ frame $\left.{ }^{-1}\right)$. Analysis was restricted to abundant species ( $N>20$ birds transect ${ }^{-1}$ ). Spearman rank correlation (Sokal \& Rohlf 1981) was used to determine whether variability, as measured by I' and D, was correlated with frame size.

The data consisted of point occurrences along continuous transects, so point process theory (Cox \& Isham 1980) was used to analyze the relation between I' and frame size under 2 conditions: scale-independent, and scale-dependent variation in distance between individuals or flocks. The analysis was checked by compu- 
ter simulation of scale-independent distribution of individuals (random individuals and random flocks) and of scale-dependent distribution of individuals (extended flocks and regularly spaced flocks). In all simulations, 60 individuals were distributed along a 120 unit line. Random individuals were simulated by choosing a random location along the line, increasing the count at this point by one, and repeating the procedure 60 times. Random flocks were simulated by choosing a random location, increasing the count at this point by an integral value, and repeating this procedure until 60 individuals were placed. Extended aggregation was simulated by choosing an arbitrary point and then placing individuals at random within 6 units of that point. Extended aggregation was also simulated as a reduction in flock size with increasing distance from a central point, as follows:

$$
20408032080402
$$

A random number generator was used to locate the central point along a 120 unit line. Regularly spaced aggregations were simulated by placing 60 individuals at random in 1 of 4 locations that were evenly spaced along the line.

Based on simulation results, scale of aggregation was defined as the frame size where the variance-tomean ratio $\left(\mathrm{I}^{\prime}\right)$ attained a maximum value. This criterion was used to determine whether scale of aggregation depended on orientation of transects (normal versus parallel to the coastline).

\section{RESULTS}

\section{Spatial variation in bird abundance}

A total of 1647 birds were seen within $300 \mathrm{~m}$ of the ship along Transect A. Of these birds, $47 \%$ were Cape Cormorants Phalacrocorax capensis, $16 \%$ were unidentified cormorants (primarily Cape Cormorants), $25 \%$ were Sabine's Gull Larus sabini, $11 \%$ were Cape Gannets Morus capensis, $2.5 \%$ were Kelp Gulls Larus dominicanus, $1.8 \%$ were Sooty Shearwaters Puffinus griseus, and $1.5 \%$ were Jackass Penguins Sphensicus demersus. Less abundant species $(\mathrm{N}<20$ birds) accounted for the remaining $1.2 \%$ of the birds.

The 6 most abundant species differed in their distribution along the transect. Sabine's Gull and Sooty Shearwaters occurred toward the middle of the transect (Fig. 2), while Cape Cormorants were concentrated near the beginning and the end of the transect (near breeding colonies). Jackass Penguins were concentrated in a single aggregation near the end of the transect. Cape Gannets and Kelp Gulls occurred in small aggregations throughout the transect.

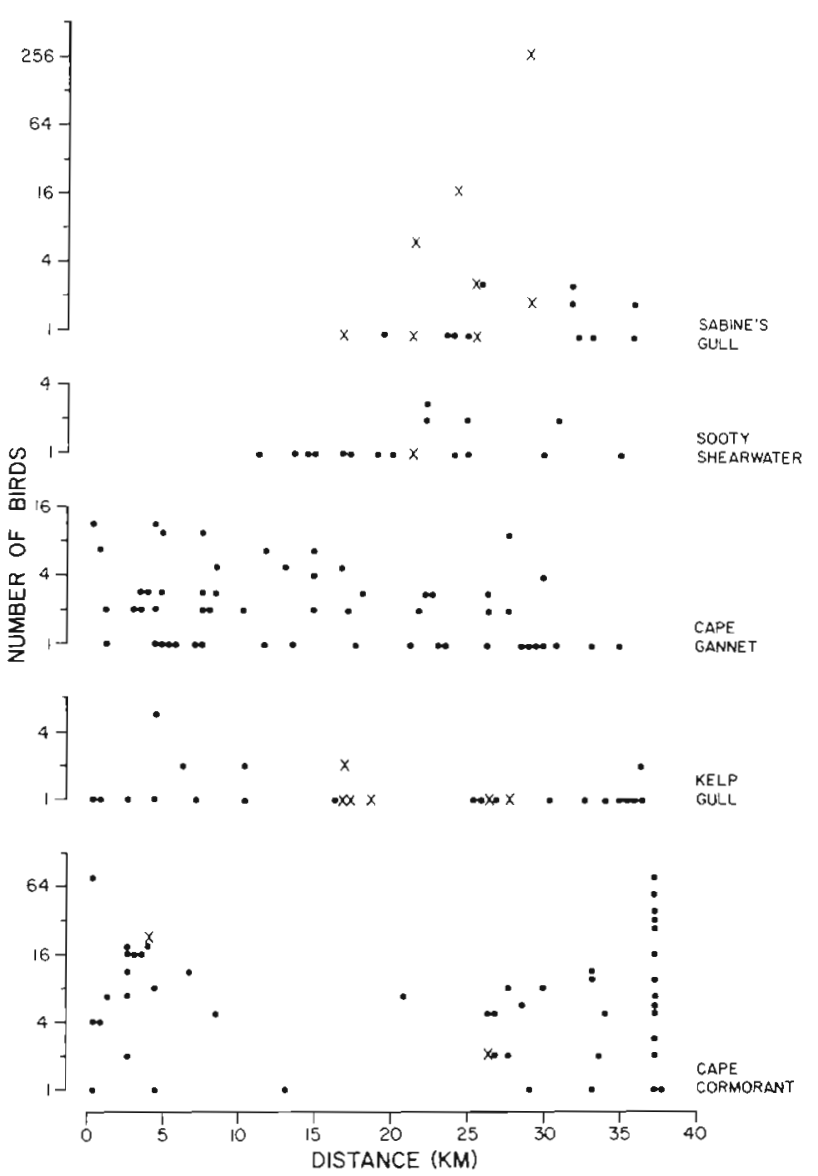

Fig. 2. Counts of abundant bird species along Transect $A$, Saldanha Bay to Dassen Island. Solid circles: flying birds; $X$ : birds on water

Intensity of aggregation, as measured by the variance-to-mean ratio computed across 120 one-minute $(0.314 \mathrm{~km})$ intervals, ranged from 1.83 in Sooty Shearwaters to 301.5 in Sabine's Gull (Table 1). Variability in bird abundance was due largely to a few high counts, as indicated by high coefficients of kurtosis and

Table 1. Abundance and dispersion of birds along Transect A, Saldanha Bay to Dassen Island, South Africa. Measurement interval $=1 \min (0.314 \mathrm{~km})$. Number of intervals $=120$. Distance $=37.7 \mathrm{~km}$. Censusing rate $=9.42$ ha min $^{-1}$. Mean: birds $\mathrm{min}^{-1}$. $\mathrm{I}^{\prime}$ : variance-to-mean ratio. D-max is goodness-offit to a normal distribution. All D-max statistics significant at $p<.01$

\begin{tabular}{|lrccccc|}
\hline \multicolumn{1}{c}{ Species } & Mean & $I^{\prime}$ & \multicolumn{2}{c}{ Skew } & Kurtosis & D-max \\
\hline Cape Cormorant & 5.74 & 126.2 & 7.79 & 69.15 & .416 \\
Sabine's Gull & 3.39 & 301.5 & 10.8 & 118.9 & .472 \\
Cape Gannet & 1.48 & 6.63 & 2.75 & 7.32 & .323 \\
Kelp Gull & .34 & 2.63 & 4.50 & 25.0 & .441 \\
Sooty Shearwater & .25 & 1.83 & 3.95 & 20.9 & .477 \\
Jackass Penguin & .21 & 25.0 & 11.0 & 120 & .528 \\
& & & & & \\
\hline
\end{tabular}


by strongly positive coefficients of skewness (Table 1). The probability that the observed distribution of counts was drawn from a normal distribution was less than $1 \%$ (Table 1 ). We concluded that the observed distribution of birds could not be described by a normal distribution, which results from a large number of independently acting components of variation.

Table 2. Correlation of Ord's D-statistic and the coefficient of dispersion ( $\left.\mathrm{I}^{\prime}\right)$ with frame length $(\mathrm{km})$ along Transect $A$. Values are Spearman rank correlation coefficients, with probability levels in parentheses

\begin{tabular}{|lll|}
\hline & Frame $\times \mathrm{D}$ & \multicolumn{1}{c|}{ Frame $\times \mathrm{I}^{\prime}$} \\
\hline Cape Cormorant & $-.84(.0001)$ & $+.60(.02)$ \\
Sabine's Gull & $-.84(.0001)$ & $+.60(<.0001)$ \\
Cape Gannet & $-.80(.0004)$ & $+.97(.0001)$ \\
Kelp Gull & $-.64(.01)$ & $-.45(.09)$ \\
Sooty Shearwater & $-.89(.0001)$ & $+.90(.0001)$ \\
Jackass Penguin & $-.09(.75)$ & $+.02(.96)$ \\
\hline
\end{tabular}

Gamma distributions, which are generated by a small number of independently acting processes (Feller 1966), can often be fit to data with strongly positive skewness. The D-statistic equals 1 for gamma distributions. The D-statistic was less than 1 in all 6 of the abundant species along Transect A, Saldanha to Dassen (Fig. 3). Distributions in the gamma family did not provide a good model of variability in bird abundance at any spatial scale along Transect $\mathrm{A}$.

Negative binomial distributions have often been used to describe aggregated populations such as zooplankton collections (Colebrook 1975) and fish catches (Taylor 1953). The D-statistic was equal to 0 in only 2 species (Kelp Gull and Sooty Shearwater) and this occurred only at frame sizes on the order of $1 \mathrm{~km}$ or less (Fig. 3). This meant that a negative binomial distribution could be used to describe fine scale spatial varia-

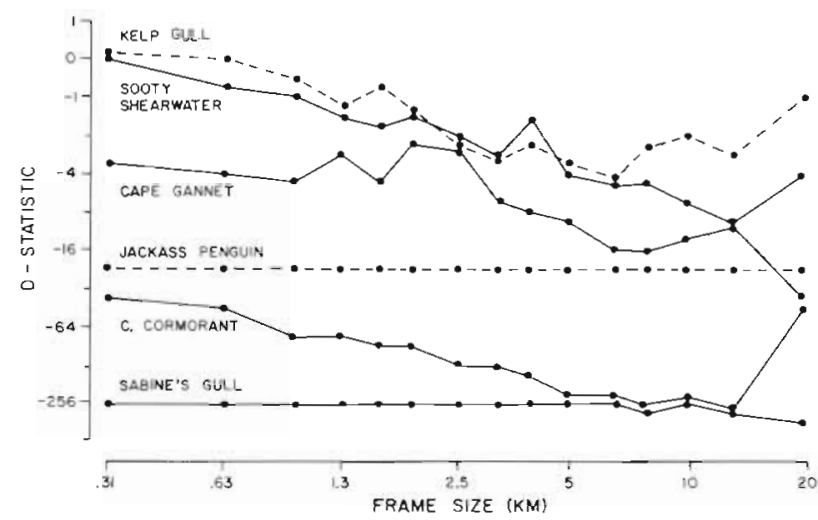

Fig. 3. Ord's D-statistic as a function of frame size for the 6 most abundant species along Transect $A$, Saldanha Bay to Dassen Island tion (1 km or less) in only 2 out of the 6 most abundant species along the transect. A negative binomial distribution could not be used to describe larger scale variation in any of the 6 abundant species.

\section{Spatial variation as a function of frame size}

Variability in bird abundance could not be characterized on the basis of a single frame size. The Dstatistic decreased significantly with increasing frame size in 5 out of the 6 most abundant species along Transect A, Saldanha to Dassen (Fig. 3, Table 2). The variance-to-mean ratio increased significantly with increasing frame size in Sooty Shearwater, Cape Cormorant, Cape Gannet, and Sabine's Gull (Table 2, Fig. 4) Maximum clumping of these species occurred at frame sizes of $4.7 \mathrm{~km}$ (Cape Cormorant), $12.6 \mathrm{~km}$ (Sooty Shearwater), and $18.8 \mathrm{~km}$ (Cape Gannet and Sabine's Gull).

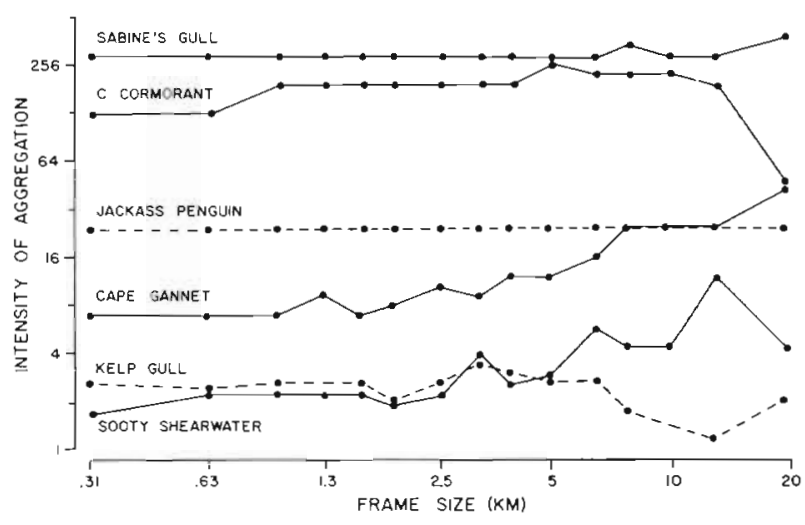

Fig. 4. Intensity of aggregation, measured by the variance-tomean ratio, of birds along Transect $A$, Saldanha to Dassen

Comparison of these results with the observed distribution of birds along the transect (Fig. 2) suggested that significant increase in the variance-to-mean ratio resulted from extended aggregation, and that the maximum value of this ratio might be used to define patch scale. This was checked by treating the occurrence of birds as a point process in 1 dimension. If the distance between successive birds along a line is independent of distance from an arbitrary point along the line, then based on point process theory, the variance-to-mean ratio based on distances between adjacent individuals will equal the average distance between individuals. Hence, the variance-to-mean ratio based on counts in non-overlapping frames will equal 1 (Cox \& Isham 1980 p. 36). This conclusion, which is based on point occurrences along a line, can be generalized to the case of arrival and departure of individuals from a zone of observation (Cox \& Isham 1980 p. 138). If the dis- 
Table 3. Correlation of Ord's D-statistic and the variance to mean ratio $\left(I^{\prime}\right)$ with frame size for simulated data. Values are Spearman rank correlation coefficients, with probability levels in parentheses

\begin{tabular}{|c|c|c|}
\hline & Frame $\times D$ & Frame $\times I^{\prime}$ \\
\hline $\begin{array}{l}60 \text { randomly placed } \\
\text { individuals }\end{array}$ & $-.41(.12)$ & $-.24(.39)$ \\
\hline 20 randomly placed flocks & $-.20(.47)$ & $-.36(.17)$ \\
\hline 4 regularly placed flocks & $+1.0\{<.0001\}$ & $-1.0(<.0001)$ \\
\hline Cluster of 60 individuals & $-.93(.0001)$ & $+.90(<.0001)$ \\
\hline $\begin{array}{l}\text { Uniform patch of } \\
60 \text { individuals }\end{array}$ & $-.96(.0001)$ & $+.96(<.0001)$ \\
\hline
\end{tabular}

tance between individuals depends on distance from an arbitrary point then the variance in counts will include a covariation term that depends on distance from the arbitrary point (Cox \& Isham 1980 Eq. 2.24). This covariance can be either positive or negative so the variance-to-mean ratio can either increase with frame size if covariance is positive, or decrease if covariance is negative. Based on this analysis, the variance-to-mean ratio of counts should be independent of frame size if the distance between individuals is independent of location along a line; it should change with frame size if the distance between individuals depends on distance from an arbitrary point.

Computer simulation showed that for randomly placed individuals and randomly placed flocks of equal size, the variance-to-mean ratio was independent of frame size (Table 3). The variance-to-mean ratio increased significantly with increasing frame size in the case of extended aggregation; it decreased significantly with increasing frame size in the case of equally spaced aggregations (Table 3 ).

Simulation results (Fig. 5) showed that the number of birds in a single, extended aggregation was approximated by the maximum value of the variance-to-mean ratio, and that the chord length of an extended patch

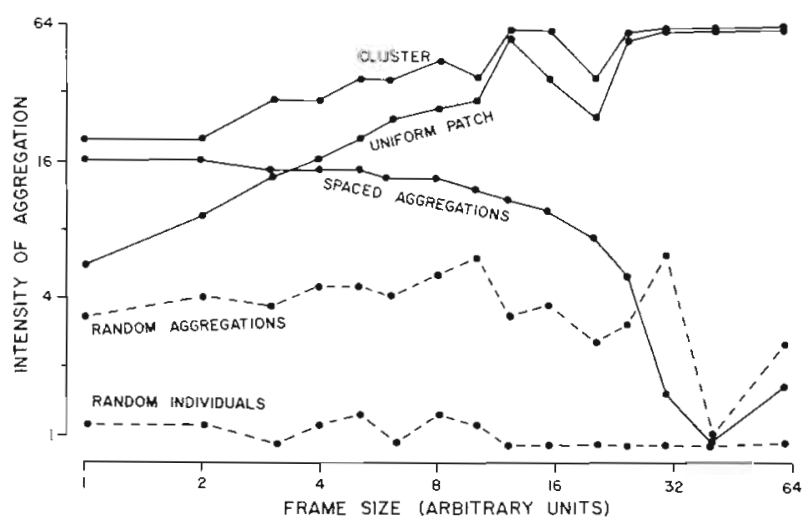

Fig. 5. Intensity of aggregation, measured by the variance-tomean ratio, of simulated bird distributions. Solid lines indicate significant $(\mathrm{p}<.05)$ rank correlation with frame size was approximated by the frame size at which maximum clumping was observed. In the case of 60 individuals placed randomly in a 12 unit long patch, the variance-to-mean ratio increased rapidly to a value of 52 at a frame size of 12 , then remained at this level at larger frame sizes (Fig. 5). In the case of 60 individuals placed in a 13 unit long cluster, the variance-to-mean ratio rose to a value of 56 at a frame size of 12 , then remained at this level at larger frame sizes (Fig. 5).

\section{Effects of transect orientation}

A total of 1054 birds were observed within $300 \mathrm{~m}$ of the ship along Transects $B, C$, and D, which ran either westward from Hout Bay, or southward from a point west of Hout Bay (Fig. 1). Of the birds seen, $53 \%$ were Cape Gannets, $8 \%$ were Sooty Shearwaters, $7 \%$ were Black-browed Albatross Diomedea melanophris, $7 \%$ were White-chinned Petrels Procellaria aequinoctialis, and $6 \%$ were Shy Albatross Diomedea cauta. Species averaging less than 20 birds transect ${ }^{-1}$ accounted for the remaining $18 \%$ of the birds observed (Table 4 ).

Extensive aggregation, as indicated by significant and positive correlation between frame size and the variance-to-mean ratio, occurred more frequently along the east-west Transects $B$ and $D$ than along the north-south Transect $C$ offshore. Extensive aggregation occurred in 3 of 5 abundant species along Transect $\mathrm{B}$, and in 4 of the same 5 species along Transect D (Table 5). None of these species showed extensive aggregation along the north-south Transect $\mathrm{C}$, even though 2 of the 5 species were more abundant along this transect than along the east-west transects (Table 4). We rejected the null hypothesis that variation in bird abundance was independent of transect orientation in the Benguela region.

Table 4. Abundance of birds along Transects B, C, and D (see text) in the Benguela upwelling region

\begin{tabular}{|lccc|} 
& \multicolumn{3}{c|}{ Transect } \\
& B & C & D \\
\hline Date (1982) & $18 \mathrm{Dec}$ & $18 \mathrm{Dec}$ & $19 \mathrm{Dec}$ \\
Start (GMT) & 0400 & 0705 & 0347 \\
Duration (min) & 180 & 120 & 168 \\
Length (km) & 41.14 & 29.63 & 45.89 \\
Heading & West & South & West \\
Bird abundance & & & \\
Cape Gannet & 371 & 61 & 129 \\
Sooty Shearwater & 32 & 20 & 32 \\
Black-browed Albatross & 10 & 61 & 8 \\
White-chinned Petrel & 16 & 29 & 32 \\
Shy Albatross & 20 & 27 & 17 \\
Other species & 82 & 47 & 60 \\
& & & \\
\hline
\end{tabular}


Table 5. Patch scale of abundant bird species along Transects $B, C$ and D. $r$ : Spearman rank correlation of the variance-tomean ratio $\left(\mathrm{I}^{\prime}\right)$ with frame length $(\mathrm{km})$; $\mathrm{p}$ : probability that $\mathrm{r}=0$. Patch scale is frame size $(\mathrm{km})$ at which $\mathrm{I}^{\prime}$ is maximum, if $p(r=0)<5 \%$

\begin{tabular}{|lrrrr|}
\hline \multicolumn{1}{|c}{ Species } & $\begin{array}{c}\text { Tran- } \\
\text { sect }\end{array}$ & $\mathrm{r}$ & $\mathrm{p}$ & $\begin{array}{c}\text { Patch } \\
\text { scale }\end{array}$ \\
\hline Cape Gannet & $\mathrm{B}$ & .46 & .07 & \\
& $\mathrm{C}$ & -.06 & .84 & \\
Sooty Shearwater & $\mathrm{D}$ & .97 & .0001 & 23 \\
& $\mathrm{~B}$ & .81 & .0001 & 6.8 \\
& $\mathrm{C}$ & .06 & .82 & \\
Black-browed Albatross & $\mathrm{D}$ & .30 & .27 & \\
& $\mathrm{~B}$ & .79 & .0002 & 20.5 \\
& $\mathrm{C}$ & -.07 & .81 & \\
White-chinned Petrel & $\mathrm{D}$ & .84 & .0001 & 11.5 \\
& $\mathrm{~B}$ & .16 & .55 & \\
Shy Albatross & $\mathrm{C}$ & -.14 & .61 & \\
& $\mathrm{D}$ & .99 & .0001 & 23 \\
& $\mathrm{~B}$ & .79 & .0002 & 20.5 \\
& $\mathrm{C}$ & .51 & .052 & \\
& $\mathrm{D}$ & .96 & $<.0001$ & 23 \\
\hline
\end{tabular}

Patch scale, as indicated by the frame size with maximum clumping, ranged from 6.8 to at least 20.5 $\mathrm{km}$ along Transect $\mathrm{B}$, and from 11.5 to at least $23 \mathrm{~km}$ along Transect $D$. This range in patch scale was as great as that observed along Transect $A$, in which maximum clumping occurred at frame sizes ranging from 4.7 to $18.8 \mathrm{~km}$. Patch scale appeared to be greater in mobile species such as the albatrosses than in less mobile species such as the Cape Cormorant, but the data were too limited to test this statistically.

\section{DISCUSSION}

Patch scale of pelagic birds along the 4 transects in the Benguela region ranged from 4.7 to at least $23 \mathrm{~km}$. These values cannot be interpreted as patch diameters, since patches may not have been circular in shape, and the ship may have passed through the edge rather than the center of a patch. Maximum patch dimension will be larger than observed chord lengths, since a ship is unlikely to encounter the center of a circular patch, or to cross a patch along its major axis.

Chord lengths in the Benguela Current were generally smaller than those reported in previous studies. In the Bering Sea Schneider (1982) reported patches with chord lengths ranging from 13 to $44 \mathrm{~km}$, while Kinder et al. (1983) reported a murre patch $12 \mathrm{~km}$ in chord length. Woodby (1984) reported average chord lengths of $35 \mathrm{~km}$ in murres in the same area of the Bering Sea. In the California Current Briggs et al. (1984) reported a phalarope patch $32 \mathrm{~km}$ in chord length. Smaller patches may have gone undetected since the minimum detectable patch in all of these studies was on the order of $12 \mathrm{~km}$.

Extensive aggregation was observed in the Benguela region along transects running outward from shore, but was not observed along an offshore transect running parallel to the shore. We rejected the hypothesis that variation in bird abundance was isotropic (independent of direction) in an anisotropically structured physical regime. This result is consistent with that of Mackas (1984) who described anisotropic variation in plankton abundance in a shelf ecosystem in the northeast Pacific. A much larger censusing effort would be needed to estimate the true frequency of extended aggregations of birds along transects normal and parallel to the coastline.

A variety of methods have been developed to measure the scale of patchiness (Ripley 1981), but these methods do not distinguish patch diameter and patch frequency. Estimates of patch diameter have often been based on explicit models of patch shape (Dobzhansky \& Wright 1943, Okubo 1980). We used point process theory to develop an estimation method that does not require an explicit model of patch shape. Morisita (1959) also developed a method that does not require an explicit model of patch shape. Morisita's method differs from ours in the following ways. First, Morisita's index $\left(\mathrm{I}_{\delta}\right)$ is an adjusted variance-to-mean ratio:

$$
\mathrm{I}_{\delta}=(\mathrm{N}-1)^{-1}\left(\mathrm{~N}-\mathrm{n}+\mathrm{I}^{\prime}\right)
$$

where $\mathrm{N}=$ total number of organisms; $\mathrm{n}=$ number of frames; $I^{\prime}=$ variance-to-mean ratio. Second, Morisita's criterion of patch size is the maximum positive increase in $\mathrm{I}_{\delta}$. Our criterion is the maximum value of $\mathrm{I}^{\prime}$. Morisita's criterion is sensitive to subclustering; our criterion emphasizes overall cluster size.

We found that patch size differed in co-occurring species. This suggests that patch formation depends on species-specific responses to the marine environment. Potentially significant sources of behavioral variation include differential response to wind (Blomqvist \& Peterz 1984), selective response to environmental cues (including differences in prey preferences), and reliance on different sensory input, such as visual or olfactory cues.

Patch size also varied within species. Predictive models of patch scale have been developed for phytoplankton (Skellam 1951, Kierstead \& Slobodkin 1953) but little is known about the factors governing patch size in mobile marine organisms, such as pelagic birds. Hoffman et al. (1981) reported differences in the rate of arrival of different species to the same feeding aggregation in Alaskan coastal waters. Individual variation in departure rates (LaCock \& Schneider 1982) might 
also contribute to variation in patch scale and intensity. The behavioral determinants of arrival and departure rates are not known, but it seems likely that both benefits (e.g. prey patchiness) and costs (e.g. flight costs) might contribute to variation in the rate of arrival and departure of birds from aggregations at sea.

We found that variability in bird abundance along transects could not be modeled as a Gaussian process. This is not unexpected in highly aggregated organisms, but ours is apparently the first demonstration of the degree to which counts of pelagic birds depart from a normal distribution. Non-Gaussian variability has 2 important implications. The first is that Gaussian variability cannot be assumed in any analysis of pelagic counts. Statistical analyses based on Gaussian variability, including standard ANOVA techniques, may have a higher Type I error than that obtained from an $F$ or $t$ distribution, especially at small sample sizes. Similarly, confidence intervals based on $\mathrm{F}$ or $\mathrm{t}$ distributions may be misleading when variability is driven by a few large counts, rather than being distributed symmetrically around a mean value.

The second implication of strong deviation from Gaussian variability is that variation in the abundance of pelagic birds is likely to be dominated by a few processes, rather than a large number of processes. Variability that is driven by a limited number of independent processes can often by described by distributions from the gamma or negative binomial families (Feller 1966). We found that gamma distributions could not be used to describe spatial variation in the abundance of pelagic birds, and that negative binomial distributions could only be used to describe local variation in bird abundance along our transects. This suggests that local variation may be due to a small number of independently acting processes, while larger scale variation in abundance is driven by interacting processes. A larger set of counts will be needed to estimate the frequency of departure from negative binomial distributions, and to determine whether deviation is typically in the direction of hyper-aggregated or contagious frequency distributions (Ord's D-statistic less than 0), as we observed along our transects.

Feeding by seabirds occurs primarily in aggregations (Duffy 1983) but our data were too limited to test whether interaction of seabirds with their prey occurs at the same scale as the observed aggregation of predators. Feeding events can be treated as point occurrences along a continuous transect and hence point process theory could be extended to the analysis of behavioral interactions between seabirds and their prey.

The methods that we used to analyze spatial variation in bird abundance are appropriate for any species whose distribution can be described as point occur- rences along continuously censused transects. Methods based on point-process theory could be applied to other species that are censused from airplanes or moving ships, such as marine mammals. Continuous counts can be made from submersible vessels, so methods based on point processes theory could be applied to non-vertebrate organisms, such gelatinous zooplankton or megabenthic animals.

Acknowledgements. We thank the Sea Fisheries Research Institute for ship time on the R. V. Trachurus, whose captain and crew made our work easier. D. C. S. thanks W. R. Siegfried for arranging his visit to Cape Town. A. Amos suggested a computational algorithm for integrating continuous seabird data with environmental data collected at inconvenient intervals. R. G. Ford suggested the use of 3rd moment statistics for analyzing seabird data. We thank A. Burger, W. Montevecchi R. A. Myers, and W. R. Siegfried for comments on the manuscript. This work was part of the Benguela Ecology Programme sponsored by the South African National Committee for Oceanographic Research. Newfoundland Institute for Cold Ocean Science Contribution No. 78.

\section{LITERATURE CITED}

Abrams, R. W., Griffiths, A. M. (1981). Ecological structure of the pelagic seabird community in the Benguela Current region. Mar. Ecol. Prog. Ser. 5: 269-277

Agenbag, J. J. (1980). General distribution of pelagic fish off South West Africa as deduced from aerial fish spotting (1971-1974 and 1977) and as influenced by hydrology. Fish. Bull. Un. S.Afr. 13: 5-67

Andrews, W. R. H., Hutchings, L. (1980). Upwelling in the southern Benguela Current. Progr. Oceanogr. 9: 1-81

Bang, N. D. (1971). The Southern Benguela Current region in February, 1966: Part II. Bathythermography and air-sea interactions. Deep Sea Res. 18: 209-224

Bartlett, M. S. (1975). The statistical analysis of spatial pattern. Chapman and Hall, London

Blomqvist, S., Peterz, M. (1984). Cyclones and pelagic seabird movements. Mar. Ecol. Prog. Ser. 20: 85-92

Box, C. E., Jenkins, C. M. (1976). Time series analysis: forecasting and control. Holden-Day, San Francisco.

Briggs, K. T., Dettman, K. F., Lewis, D. B., Tyler, W. B. (1984). Phalarope feeding in relation to autumnal upwelling off California. In: Nettleship, D. N., Sanger, G. A., Springer, P. F, (ed.) Marine birds: their feeding ecology and commercial fisheries relationships. Can. Wildlife Serv. Spec. Pub., Ottawa, p. 51-64

Colebrook, J. M. (1975). The continuous plankton recorder survey: computer simulation of some aspects of the survey. Bull. Mar. Biol. 8: 143-166

Cox, D. R., Isham, V. (1980). Point processes. Chapman and Hall, London

Crawford, R. J. M., Shelton, P. A. (1978). Pelagic fish and seabird interrelationships off the coasts of South-West Africa and South Africa. Biol Conserv, 14: 51-94

Dobzhansky, T., Wright, S. (1943). Genetics of natural populations. X. Dispersion rate in Drosophila pseudoobscura. Genetics 28: 304-340

Duffy, D. C. (1983). The foraging ecology of Peruvian seabirds. Auk 100: 800-810 
Feller, W. (1966). An introduction to statistical theory and applications. John Wiley, New York

Grieg-Smith, P. (1964). Quantitative plant ecology, 2nd ed. Butterworths, London

Hoffman, W., Heinemann, D., Wiens, J. A. (1981). The ecology of seabird feeding flocks in Alaska. Auk 98: 437-456

Kierstead, H., Slobodkin, L. B. (1953). The size of water masses containing plankton blooms. J. mar. Res. 12: 141-147

Kinder, T. H., Hunt, G. L., Schneider, D., Schumacher, J. D. (1983). Correlations between seabirds and oceanic fronts around the Pribilof Islands, Alaska. Estuar. coast. Shelf Sci. 16: 309-319

LaCock, G., Schneider, D. (1982). Duration of ship following by wandering albatrosses, Diomedea exulans. Cormorant 10: $105-108$

Mackas, D. L. (1984). Spatial autocorrelation of plankton community composition in a continental shelf ecosystem. Limnol. Oceanogr. 29: 451-471

Mackas, D. L., Boyd, C. M. (1979). Spectral analysis of zooplankton spatial heterogeneity. Science 204: 62-64

Morisita, M. (1959). Measuring of the dispersion of individuals and analysis of the distributional patterns. Mem. Fac. Sci. Kyushu Univ. Ser. E 2: 215-235

Okubo, A. (1980), Diffusion and ecological problems. Springer-Verlag, New York

Ord, J. K. (1967). On a system of discrete distributions. J. R. Statist. Soc. 130: 232-238
Ord, J. K. (1972). Families of frequency distributions. Griffin, London

Pielou, E. C. (1977). Mathematical ecology. John Wiley, New York

Platt, T. (1972). Local phytoplankton abundance and turbulence. Deep Sea Research 19: 183-187

Ripley, B. D. (1981). Spatial statistics. John Wiley, New York

Schneider, D. (1982). Fronts and seabird aggregations in the southeastern Bering Sea. Mar. Ecol. Prog. Ser. 10: 101-103

Skellam, J. G. (1951). Random dispersal in theoretical populations. Biometrika 38: 196-218

Sokal, R. R., Rohlf, F. J. (1981). Biometry, 2nd ed. Freeman, San Francisco

Stommel, H. 1 (963). Varieties of oceanographic experience. Science 139: 572-576

Tasker, M. L., Hope Jones, P., Dixon, T., Blake, B. F. (1984). Counting seabirds at sea from ships: A review of methods and a suggestion for a standardized approach. Auk 101: $567-577$

Taylor, C. G. (1953). The nature of variability in trawl catches. Bull. U. S. Bur. Fish. 54: 145-156

Thomas, R. M. (1980). A note on swarms of Nyctiphanes capensis (Hansen) larvae off South West Africa. Fish Bull Un. S.Afr. 13: 21-23

Woodby, D. (1984). The April distribution of murres and prey patches in the southeastern Bering Sea. Limnol. Oceanogr. 29: 181-188

This paper was presented by Professor R. L. Haedrich; it was accepted for printing on June 3, 1985 